\title{
State-Dependent Enhancement of Subthreshold A-Type Potassium Current by 4-Aminopyridine in Tuberomammillary Nucleus Neurons
}

\author{
Alexander C. Jackson and Bruce P. Bean \\ Department of Neurobiology, Harvard Medical School, Boston, Massachusetts 02115
}

\begin{abstract}
A-type potassium current $\left(I_{\mathrm{A}}\right)$ both activates and inactivates at subthreshold voltages. We asked whether there is steady-state $I_{\mathrm{A}}$ at subthreshold voltages, using dissociated mouse tuberomammillary nucleus neurons, pacemaking neurons with large $I_{\mathrm{A}}$ currents in which subthreshold $I_{\mathrm{A}}$ might regulate firing frequency. With slow depolarizing voltage ramps $(20 \mathrm{mV} / \mathrm{s})$, there was no discernible component of steady-state outward current in the range of -70 to $-40 \mathrm{mV}$. However, faster ramps of $50-100 \mathrm{mV} / \mathrm{s}$, similar to the rate of spontaneous depolarization during pacemaking, did evoke subthreshold outward currents. Ramp-evoked current at subthreshold voltages was unaffected by $10 \mathrm{~mm}$ tetraethylammonium and likely represents $I_{\mathrm{A}}$, because its voltage dependence overlaps that of $I_{\mathrm{A}}$ activation (midpoint near $-44 \mathrm{mV}$ ) and inactivation (midpoint near $-85 \mathrm{mV}$ ). However, although 4-aminopyridine (4-AP) inhibited peak $I_{\mathrm{A}}$ activated by step depolarizations as expected $\left(\mathrm{IC}_{50}, \sim 1 \mathrm{mM}\right.$ ), ramp-evoked current was instead dramatically enhanced (current at -40 $\mathrm{mV}$ evoked by $50 \mathrm{mV} / \mathrm{s}$ ramp enhanced $>15$-fold by $10 \mathrm{~mm} 4-\mathrm{AP}$ ). In cell-attached recordings of spontaneous pacemaking, $10 \mathrm{~mm} 4-\mathrm{AP}$ slowed rather than speeded firing, consistent with enhancement of subthreshold $I_{\mathrm{A}}$. Also consistent with such enhancement, 4-AP also greatly increased the latency to first spike after long hyperpolarizations. The striking enhancement of $I_{\mathrm{A}}$ during depolarizing ramps can be explained by a model in which 4-AP binds tightly to closed channels but must unbind before channels can inactivate. Thus, the state dependence of 4-AP binding to the channels underlying $I_{\mathrm{A}}$ can result in effects on firing patterns opposite to those expected from simple block of $I_{\mathrm{A}}$.
\end{abstract}

Key words: $I_{\mathrm{A}} ; I_{\mathrm{K}}$; spontaneous firing; pacemaking; spike latency; Kv4.2

\section{Introduction}

Multiple types of voltage-dependent potassium channels are present in neurons and play major roles in regulating firing patterns. Among these are a class of potassium currents called A-type potassium currents $\left(I_{\mathrm{A}}\right)$ that can be activated at subthreshold voltages and also show pronounced inactivation with sustained depolarization at these voltages. Such currents enable neurons to fire rhythmically at low frequencies, with $I_{\mathrm{A}}$ during interspike intervals undergoing a sequence of activation followed by inactivation (Connor and Stevens, 1971a,b; Rush and Rinzel, 1995). In mammalian central neurons, $I_{\mathrm{A}}$ can originate from potassium channels encoded by several molecular entities, including Kv1.4, Kv4.2, and Kv4.3. Kv4 family channels appear to underlie $I_{\mathrm{A}}$ in somatodendritic membranes (Sheng et al., 1992; Serodio and Rudy, 1998; Song et al., 1998; Malin and Nerbonne, 2000; Shibata et al., 2000; Tkatch et al., 2000; Liss et al., 2001; Kim et al., 2005; Strassle et al., 2005; Yuan et al., 2005), whereas Kv1.4 is targeted

\footnotetext{
Received March 1, 2007; revised Aug. 9, 2007; accepted Aug. 19, 2007. This work was supported by National Institutes of Health Grants GM070774 and NS36855.

Correspondence should be addressed to Bruce P. Bean, Department of Neurobiology, Harvard Medical School, 220 Longwood Avenue, Boston, MA 02115. E-mail: bruce_bean@hms.harvard.edu.

A. C. Jackson's present address: Department of Cellular and Molecular Pharmacology, University of California, San Francisco, San Francisco, CA 94143.

DOI:10.1523/JNEUROSCI.0935-07.2007

Copyright $\odot 2007$ Society for Neuroscience $\quad 0270-6474 / 07 / 2710785-12 \$ 15.00 / 0$
}

to axons and terminals (Sheng et al., 1992; Cooper et al., 1998). Somatodendritic $I_{\mathrm{A}}$ is often distinguished from other components of potassium current by its pharmacology. Somatodendritic $I_{\mathrm{A}}$ is relatively resistant to external tetraethylammonium (TEA) (half-block, $>100 \mathrm{~mm}$ ) and moderately sensitive to 4-aminopyridine (4-AP) with a typical half-blocking concentration of $\sim 1 \mathrm{~mm}$ (Segal et al., 1984; Zbicz and Weight, 1985; Huguenard et al., 1991; Klee et al., 1995; Locke et al., 1997; Song et al., 1998) (for review, see Song, 2002; Jerng et al., 2004b). Thus, the functional roles of $I_{\mathrm{A}}$ are often studied by examining the effect of 3-10 mM 4-AP.

We set out to explore the functional roles of $I_{\mathrm{A}}$ in regulating the firing activity of histaminergic neurons in the tuberomammillary nucleus (TMN) of the hypothalamus. These neurons fire spontaneously in the absence of synaptic input (Haas and Reiner, 1988; Llinás and Alonso, 1992; Uteshev et al., 1995), and they have a prominent $I_{\mathrm{A}}$ (Greene et al., 1990; Llinás and Alonso, 1992). We were especially interested in exploring whether there is steady-state $I_{\mathrm{A}}$ flowing at subthreshold potentials and whether $I_{\mathrm{A}}$ plays a role in regulating spontaneous firing frequency, as in some other pacemaking neurons (Liss et al., 2001; Hahn et al., 2003, 2006). In voltage-clamp experiments, we found that, although peak $I_{\mathrm{A}}$ elicited by step depolarizations is inhibited as expected by 4-AP $\left(\mathrm{IC}_{50}, \sim 1 \mathrm{mM}\right)$, when $I_{\mathrm{A}}$ is activated by depolarizing ramps of voltage at speeds that mimic spontaneous depolarization dur- 

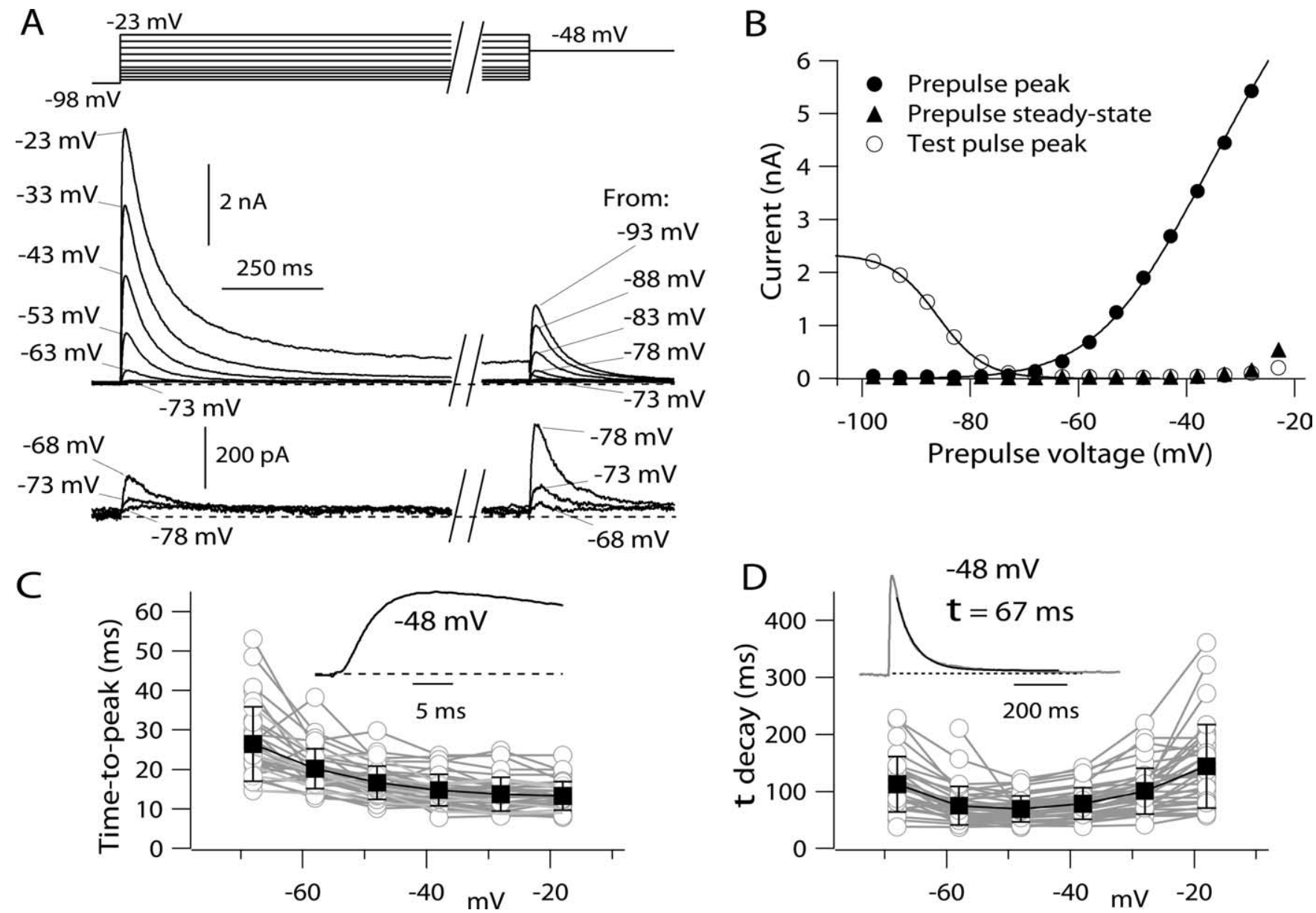

Figure 1. Step-evoked potassium currents in dissociated mouse TMN neurons. $A$, Currents elicited by voltage protocol designed to measure both activation and inactivation. Bottom, Currents for small depolarizations shown at increased resolution. B, Voltage dependence of peak current elicited by steps from $-98 \mathrm{mV}$ (filled circles), steady-state current at the end of the $2 \mathrm{~s}$ step (filled triangles), and peak current during a subsequent step to $-48 \mathrm{mV}$ (open circles), which assayed the degree of inactivation of transient current during the 2 s prepulse. The solid curve through the open circles is drawn according to a Boltzmann curve describing inactivation, $I_{\max } /\left[1+\exp \left(\left(V-V_{\mathrm{h}}\right) / k\right)\right]$, with $I_{\max }=2.3 \mathrm{nA}, V_{\mathrm{h}}=-86 \mathrm{mV}$, and $k=4.3 \mathrm{mV}$. The solid curve through the closed circles is drawn according to a Boltzmann curve describing activation, $G_{\max }\left(V-E_{K}\right) /\left[1+\exp \left(-\left(V-V_{\mathrm{h}}\right) / k\right)\right]$, where $G_{\max }$ (maximal conductance) $=100 \mathrm{nS}, V$ is the test potential, $E_{\mathrm{K}}$ (potassium equilibrium potential) $=-92 \mathrm{mV}, V_{\mathrm{h}}$ (midpoint) $=-44 \mathrm{mV}$, and $k$ (slope factor) $=10.4 \mathrm{mV}$. In collected values from 38 neurons, average values (mean $\pm S D$ ) for $V_{\mathrm{h}}$ were $-44 \pm 5 \mathrm{mV}$ and for $k$ were $9.2 \pm 1.1 \mathrm{mV}$. C, Time-to-peak of total potassium current as a function of voltage in $38 \mathrm{TMN}$ neurons (data from each cell shown as gray symbols). The solid symbols show mean $\pm S D$ at each voltage for the values from the 38 cells. Inset, Rising phase of current evoked by a step from -98 to $-48 \mathrm{mV}$. D, Inactivation kinetics as a function of voltage in 38 TMN neurons (gray symbols). Decay of current during the $2 \mathrm{~s}$ prepulse was fit by a single exponential decay (inset shows an example for a step to $-48 \mathrm{mV}$ ). The solid symbols show mean $\pm S D$ at each voltage for the values from the 38 cells.

ing pacemaking, the current can be dramatically enhanced by 4-AP. Consistent with such an enhancement, in current-clamp experiments, application of 4-AP frequently resulted in slower firing rather than the faster firing expected if $I_{\mathrm{A}}$ flows during interspike intervals and is blocked by 4 -AP. The enhancement of $I_{\mathrm{A}}$ during depolarizing ramps at subthreshold voltages can be understood if channels with 4-AP bound are unable to inactivate and consequently unbind 4-AP as depolarization progresses.

\section{Materials and Methods}

TMN cell preparation. We examined neurons isolated from the ventral tuberomammillary region of the hypothalamus from mice aged 13-28 d postnatal, with most data coming from rats aged $17-21 \mathrm{~d}$. The procedure for dissociation was adapted from those previously used for dissociation of TMN neurons from rat brain (Uteshev et al., 1995; Taddese and Bean, 2002). Mice were deeply anesthetized with isoflurane and quickly decapitated into an ice-cold slurry of a HEPES-buffered high-sucrose slicing solution composed of the following (in mM): $30 \mathrm{Na}_{2} \mathrm{SO}_{4}, 2 \mathrm{~K}_{2} \mathrm{SO}_{4}, 185$ sucrose, 10 glucose, $10 \mathrm{HEPES}, 0.5 \mathrm{CaCl}_{2}$, and $6 \mathrm{MgCl}_{2}, \mathrm{pH}$ 7.4. Blocks of brain containing the hypothalamus and intact optic nerves were blocked off and deposited into the sucrose slurry. The blocks were immediately affixed to the chilled platform of the slicing chamber, caudal side down, with cyanoacrylate glue. A vibrating tissue slicer (DTK-1000; DSK, Dosaka, Japan) was used to cut coronal hypothalamic slices $(300 \mu \mathrm{m}$ thick). Typically, three or four transverse slices containing the tuberomammillary nucleus were obtained. The slices were then transferred to the enzymatic dissociation solution, which consisted of $2.5 \mathrm{mg} / \mathrm{ml}$ protease XXIII (Sigma, St. Louis, MO) in sucrose solution and were incubated for $10 \mathrm{~min}$ at $34^{\circ} \mathrm{C}$. After enzyme treatment, the slices were rinsed in room temperature sucrose solution and placed in cold $\left(4^{\circ} \mathrm{C}\right)$ sucrose solution containing $1 \mathrm{mg} / \mathrm{ml}$ trypsin inhibitor and $1 \mathrm{mg} / \mathrm{ml}$ bovine serum albumin, in which the TMN was cut out of the slices under a dissecting microscope. Immediately before recording, single chunks of tissue were placed in a vial with a small volume of the storage sucrose solution and gently triturated through a fine-bore, fire-polished Pasteur pipette, generating a suspension of dissociated cells. A drop of the cell suspension was placed onto the glass-bottomed recording chamber and allowed to settle for $\sim 5 \mathrm{~min}$ before rinsing away the sucrose solution and detritus by gentle flow of extracellular bath solution.

Recordings were made from a population of large neurons that generally had three or more dendritic processes, previously described to correspond to histaminergic projection neurons (Furukawa et al., 1994; 

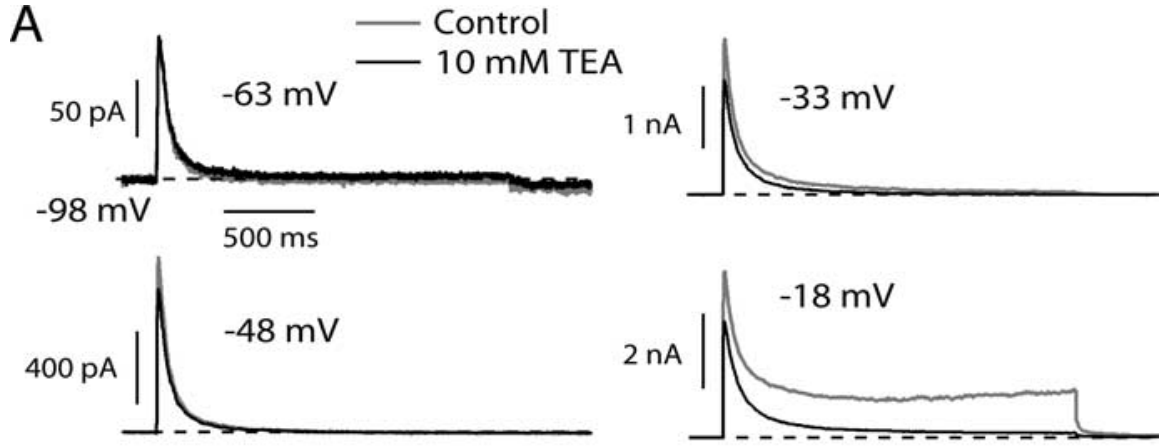

B

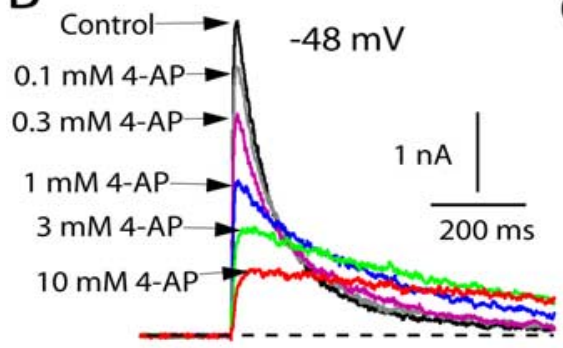

$-98 \mathrm{mV}$

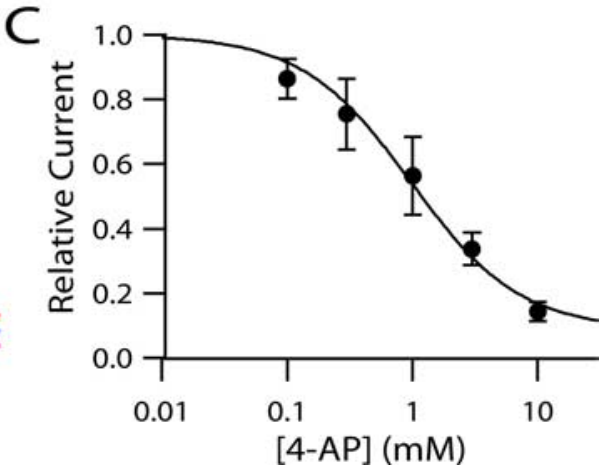

Figure 2. Sensitivity of potassium currents in TMN neurons to external TEA and 4-AP.A, Effect of $10 \mathrm{~mm}$ TEA (externally applied) on total potassium current evoked by depolarizing steps. $\boldsymbol{B}$, Effect of increasing concentrations of 4-AP (externally applied) on potassium current evoked by a step from -98 to $-48 \mathrm{mV}$. C, Dose-response relationship for 4-AP inhibition of peak potassium current. Points show mean \pm SD for four experiments like that in $\boldsymbol{B}$. The solid curve corresponds to 1:1 binding with a dissociation constant of $0.88 \mathrm{~mm} 4-\mathrm{AP}$ and a saturating block of $97 \%$.

Uteshev et al., 1995). In previous experiments with rat tuberomammillary neurons using an identical dissociation procedure, virtually all neurons with this morphology were found to stain for adenosine deaminase, a marker for histaminergic neurons (Taddese and Bean, 2002). In recordings from $>100$ neurons, the electrophysiological characteristics of all but a few neurons were highly stereotyped: spontaneous firing at $0.5-7$ $\mathrm{Hz}$, wide action potentials, and prominent A-type potassium current in voltage clamp. All of these features correspond to those previously described for histaminergic neurons (Haas and Reiner, 1988; Llinás and Alonso, 1992; Furukawa et al., 1994; Uteshev et al., 1995).

Very rarely, cells had characteristics more like those expected from interneurons, including more narrow action potentials and small A-type current, and such cells were not used in the series of experiments described here.

Electrophysiological recording and solutions. Recordings were made using an Axopatch 200B or Multiclamp 700B amplifier (Molecular Devices, Foster City, CA). Electrodes were pulled from borosilicate glass (VWR, West Chester, PA) and had resistances from 1.5 to $4 \mathrm{M} \Omega$ when filled with the internal solution, which consisted of the following (in $\mathrm{mM}$ ): 123 K-methanesulfonate, $9 \mathrm{NaCl}, 1.8 \mathrm{MgCl}_{2}, 0.9$ EGTA, 9 HEPES, 14 Triscreatine $\mathrm{PO}_{4}, 4 \mathrm{Mg}$-ATP, and 0.3 Tris-GTP, $\mathrm{pH}$ adjusted to 7.2 with $\mathrm{KOH}$. Reported membrane potentials are corrected for a liquid junction potential of $-8 \mathrm{mV}$ between the internal solution and the Tyrode's solution in which current was zeroed before sealing onto the cell, measured using a flowing $3 \mathrm{~m} \mathrm{KCl}$ reference electrode (Neher, 1992). Electrodes were wrapped with Parafilm from the shank to near the tip to reduce pipette capacitance and permit optimal series resistance compensation.

The standard external Tyrode's solution consisted of the following (in $\mathrm{mm}): 150 \mathrm{NaCl}, 3.5 \mathrm{KCl}, 1.2 \mathrm{CaCl}_{2}, 1 \mathrm{MgCl}_{2}, 10 \mathrm{HEPES}$, and 10 glucose, $\mathrm{pH} 7.4$ with $\sim 5 \mathrm{~mm} \mathrm{NaOH}$. Tetrodotoxin $(300 \mathrm{~nm})$ was present in all solutions to block sodium currents. Some initial experiments were done with addition of $0.1 \mathrm{mM} \mathrm{Cd}^{2+}$ or replacement of $\mathrm{Ca}^{2+}$ by $\mathrm{Co}^{2+}$, with the idea of eliminating possible contributions of calcium currents or calcium-activated potassium currents to subthreshold currents. How- ever, there were clear changes in the voltage dependence of $I_{\mathrm{A}}$ with these changes in divalents, as has been described previously (Mayer and Sugiyama, 1988; Song et al., 1998). Thus, we considered it preferable to do experiments with physiological divalent ion concentrations. Overlap of calcium current with $I_{\mathrm{A}}$-mediated currents appeared to be negligible under most circumstances. There was sometimes a small contribution of calcium current at voltages positive to $-50 \mathrm{mV}$, evident as a small inward current elicited by slow ramps when the rampevoked current was corrected for linear conductance (see Figs. $3 B, 4 B$ ). However, this current did not affect measurements of $I_{\mathrm{A}^{-}}$ mediated outward current for ramps of 50 $\mathrm{mV} / \mathrm{s}$ or slower, in which outward current reached a peak below $-50 \mathrm{mV}$. For ramps of $100 \mathrm{mV} / \mathrm{s}$, peak outward current (reached near -50 to $-40 \mathrm{mV}$ ) might be slightly underestimated because of the presence of inward calcium current, but the error was typically $<10-$ $20 \%$ (judged by comparison with the inward current elicited by a $20 \mathrm{mV} / \mathrm{s}$ ramp in the same cell) (see Figs. 3B, $4 B$ ).

Solution changes were effected by moving the cells in front of a horizontal array of 13 quartz flow pipes (inner diameter, $252 \mu \mathrm{m}$; outer diameter, $356 \mu \mathrm{m})$. Experiments were done at room temperature $\left(20-24^{\circ} \mathrm{C}\right)$. Statistics are reported as mean $\pm \mathrm{SD}$.

Acquisition and analysis. Data acquisition was performed using pCLAMP 9 (Molecular Devices), and data analysis was done using pCLAMP9 and IGORPro, version 4.06 (Wavemetrics, Lake Oswego, OR), using DataAccess (Bruxton, Seattle, WA) to read pClamp files into IGOR. Cell capacitance was measured by subtracting capacitative transients recorded for a $10 \mathrm{mV}$ hyperpolarization from -78 to $-88 \mathrm{mV}$ just before and just after breaking through into the cell. When recording ionic currents, capacitative transients were reduced by using electronic capacitance compensation. For voltage protocols using step depolarizations, current records were corrected for small leak and remaining capacitative currents, using 5 or $10 \mathrm{mV}$ hyperpolarizing steps (usually from -90 to $-95 \mathrm{mV}$ ) to define linear capacitance and leak currents and then subtracting appropriately scaled currents for larger steps of voltage. No correction was made for the protocols using ramp voltage commands.

\section{Results}

\section{$I_{\mathrm{A}}$ in dissociated tuberomammillary neurons}

As previously described from recordings from TMN neurons in rat brain slice (Haas and Reiner, 1988; Greene et al., 1990; Llinás and Alonso, 1992), the overall depolarization-activated potassium current in dissociated mouse TMN neurons was dominated by a large inactivating potassium current (Fig. 1A,B). From a holding potential of $-98 \mathrm{mV}$, depolarizing voltage steps began to activate detectable current at voltages positive to about $-75 \mathrm{mV}$. The current activated by steps to voltages between $-70 \mathrm{mV}$ and about $-40 \mathrm{mV}$ typically reached a peak in 15-25 $\mathrm{ms}$ and decayed nearly completely over several hundred milliseconds (Fig. 1C,D). In averaged results from 38 cells, current activated by a step to $-48 \mathrm{mV}$ reached a peak of $998 \pm 319 \mathrm{pA}$ in $20 \pm 5 \mathrm{~ms}$ and inactivated (with a time constant of $71 \pm 24 \mathrm{~ms}$ ) essentially completely during a $2 \mathrm{~s}$ step, to a steady state of $-0.3 \pm 2.0 \%$ of the peak value. For depolarizations positive to $-30 \mathrm{mV}$, current was also dominated by a rapidly inactivating component, but there was in addition a significant steady-state component. For steps to 
$-18 \mathrm{mV}$, current peaked in $13 \pm 3 \mathrm{~ms}$ to an average value of $3.9 \pm 1.4 \mathrm{nA}$ and inactivated with a time constant of $177 \pm 203$ ms to a steady state that was $15 \pm 11 \%$ of peak $(n=38)$.

The prominent inactivation of potassium current was also evident in the sensitivity of step-evoked current to depolarized holding potentials or long prepulses. In the protocol shown in Figure $1 A, 2$-slong pulses from $-98 \mathrm{mV}$ to different voltages were followed by a test pulse to $-48 \mathrm{mV}$. The current during this test pulse showed a steep dependence on prepulse voltage, declining from maximal to near zero as the prepulse changed from -98 to $-68 \mathrm{mV}$ (Fig. $1 \mathrm{~B}$ ). When fit by a Boltzmann curve, the availability of potassium current activated at $-48 \mathrm{mV}$ had a midpoint of $-85 \pm 2 \mathrm{mV}$ and a slope factor of $4.2 \pm 0.4 \mathrm{mV}(n=38)$.

We next examined the sensitivity of potassium current in tuberomammillary neurons to inhibition by external TEA and 4-AP. External TEA at concentrations up to $10 \mathrm{~mm}$ had little or no effect on the predominant transient current elicited by depolarization to voltages between -70 and $-30 \mathrm{mV}$ but inhibited the smaller component of steady-state current activated at more positive voltages (Fig. $2 \mathrm{~A}$ ). In contrast, 4-aminopyridine inhibited the transient current inhibited by a step to -48 $\mathrm{mV}$ in a dose-dependent manner, with half-block near $1 \mathrm{~mm} 4$-AP (Fig. $2 \mathrm{~B}$ ). In collected results, $1 \mathrm{~mm}$ 4-AP inhibited peak current for a step from -98 to -48 $\mathrm{mV}$ by $44 \pm 12 \%$ and $10 \mathrm{~mm} 4$-AP inhibited the current by $85 \pm 3 \%(n=4)$ (Fig. $2 C)$. These results are consistent with those in other mammalian neurons showing low sensitivity of somatodendritic A-type potassium current to external TEA and moderate sensitivity to 4-AP (Segal et al., 1984; Huguenard et al., 1991; Bouskila and Dudek, 1995; Klee et al., 1995; Locke et al., 1997; Song et al., 1998). The high TEA sensitivity of the steadystate current activated by stronger depolarizations suggests that this component of current originates from different channel types than those underlying the transient current.

In addition to inhibiting peak transient current, 4-AP clearly affected the kinetics of the current by slowing its decay. In fact, with 4 -AP concentrations $>1 \mathrm{~mm}$, although the peak current was inhibited substantially, after $\sim 200-300 \mathrm{~ms}$ the current was actually larger in the presence of 4-AP than in control (Fig. 2 B). Such "crossover" of the decay phase of $I_{\mathrm{A}}$ when inhibited by 4-AP has been evident in a number of previous experiments in other cell types (Thompson, 1982; Kehl, 1990; Castle and Slawsky, 1992; Tseng et al., 1996; Koyama and Appel, 2006).

\section{$I_{\mathrm{A}}$ activated by voltage ramps}

During normal spontaneous firing in TMN neurons, the slow spontaneous depolarization that underlies pacemaking occurs over a voltage range of about -70 to $-50 \mathrm{mV}$ (Haas and Reiner, 1988; Stevens and Hass, 1996; Taddese and Bean, 2002). $I_{\mathrm{A}}$ acti- vates at voltages within this range. Thus, it is plausible that subthreshold $I_{\mathrm{A}}$ might serve to regulate the frequency of pacemaking, as has been proposed for other pacemaking neurons (Aghajanian, 1985; Liss et al., 2001; Hahn et al., 2003, 2006). However, because in the steady state $I_{\mathrm{A}}$ inactivates over a more negative voltage range than it activates, the magnitude of $I_{\mathrm{A}}$ during the interspike interval of spontaneous firing must depend on the relative kinetics of inactivation and activation and is difficult to predict from currents elicited by step depolarizations. We therefore explored whether there is steady-state $I_{\mathrm{A}}$ at subthreshold voltages by examining potassium currents elicited by slow voltage ramps. We used ramps with rates of voltage change that are typical of those during normal spontaneous firing. First, we quantified the rate of spontaneous depolarization during the interspike interval in a number of spontaneously firing tuberomammillary neurons. The interspike slope during the spontaneous firing of dissociated TMN neurons varied between 25 and $138 \mathrm{mV} / \mathrm{s}$, with an average value of $65 \pm 34 \mathrm{mV} / \mathrm{s}$ (mean $\pm \mathrm{SD}, n=13$ ). Figure 3 shows the currents flowing in response to depolarizing ramps of three speeds $(20,50$, and $100 \mathrm{mV} / \mathrm{s})$, chosen to span this range. In the presence of TTX to block the persistent sodium current present in these neurons (Llinás and Alonso, 1992; Uteshev et al., 1995; Stevens and Haas, 1996; Taddese and Bean, 2002), there 
A
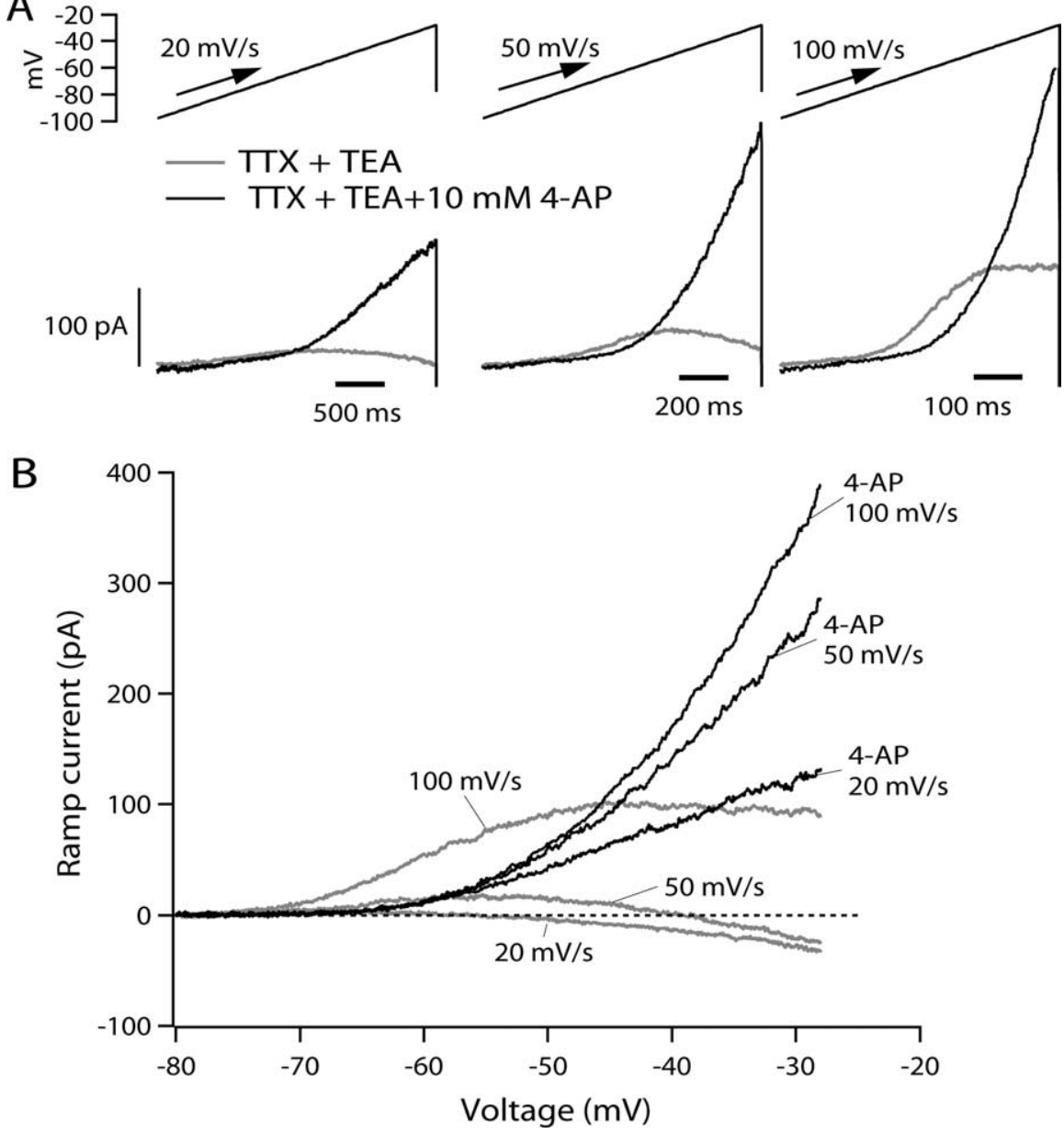

Figure 4. Effect of 4-AP on ramp-evoked current. $A$, Current evoked by ramp waveforms delivered at 20,50, and $100 \mathrm{mV} / \mathrm{s}$ before (black traces) and after (red traces) application of $10 \mathrm{~mm}$ 4-AP with a background of $10 \mathrm{~mm}$ TEA and $300 \mathrm{~nm}$ TTX. $\boldsymbol{B}$, Current-voltage relationships for ramp-evoked current before and after application of 4-AP. Leak current predicted by linear fit between -95 and $-80 \mathrm{mV}$ was subtracted from each trace.

were outward currents activated by the ramps, with characteristics that depended on the speed of the ramp. With all three speeds of the ramp, there was a component of outward current that began to activate near $-40 \mathrm{mV}$ and increased steeply from -40 to $-20 \mathrm{mV}$. This component of current was not dramatically different when elicited by the ramps at different speeds, and it was blocked by $10 \mathrm{~mm}$ TEA. Thus, it likely corresponds to a population of non- $I_{\mathrm{A}}$, non-inactivating potassium channels. There was another component of outward current whose presence and size depended strongly on the ramp speed. This component was most clearly defined in the presence of 10 mM TEA. It was not evident with ramps at $20 \mathrm{mV} / \mathrm{s}$; with ramps at this speed in the presence of $10 \mathrm{~mm}$ TEA, the only deviation from linear (ohmic) behavior was a small inward current activated positive to $-50 \mathrm{mV}$. This most likely represents a small component of steady-state calcium current. With ramps of 50 or $100 \mathrm{mV} / \mathrm{s}$, however, there was also a component of outward current that began to activate near -70 $\mathrm{mV}$ and was larger for faster ramps, increasing from $14 \pm 8 \mathrm{pA}$ at $50 \mathrm{mV} / \mathrm{s}$ (peak current occurring at $-56 \pm 3 \mathrm{mV}$ ) to $64 \pm 28 \mathrm{pA}$ at $100 \mathrm{mV} / \mathrm{s}$ (peak current occurring at $-46 \pm 5 \mathrm{mV} ; n=10$ ).

The component of outward current with strong dependence on ramp speed and a relatively negative range of activation seems likely to originate from the channels underlying $I_{\mathrm{A}}$. The lack of effect of TEA on this current rules out any contribution of BK calcium-activated potassium currents, and the steep increase with increasing ramp speed is opposite to what would be expected for any component of SK current. The strong dependence of this component of current on ramp speed suggests that, at the slowest ramp speeds, the channels inactivate essentially completely before they activate. At faster ramp speeds, there is apparently some activation before inactivation, such that with ramp speeds of $50-100 \mathrm{mV} / \mathrm{s}$, the current first activates detectably near $-70 \mathrm{mV}$, reaches a peak near $-40 \mathrm{mV}$, and then declines. Interestingly, this component of current shows significant activation with ramp speeds corresponding to the rate of interspike depolarization occurring during normal pacemaking of the neurons, suggesting that flow of $I_{\mathrm{A}}$ during the interspike interval may help to regulate pacemaking frequency.

4-AP enhancement of ramp-evoked $I_{\mathrm{A}}$ To test the idea that this component of current arises from $I_{\mathrm{A}}$ channels, we tested whether it was blocked by 4-AP. Much to our surprise, however, 4-AP consistently enhanced rather than blocked the component of ramp-evoked outward current elicited in the presence of $10 \mathrm{~mm}$ TEA (Fig. 4). This enhancement was seen in 10 of 10 cells. The enhancement of ramp-evoked outward current occurred regardless of whether or not $10 \mathrm{~mm}$ TEA was present (data not shown). In the absence of TEA, it appeared that the TEA-sensitive, ramp speed-insensitive component of current was unaffected by 4-AP. Because 4-AP appeared to have its enhancing effect on current that was not blocked by TEA, we focused our attention on its effects with TEA present. The enhancing effect of 4-AP was most striking at ramp speeds of 20/s, at which there was generally no detectable nonohmic outward current in the presence of $10 \mathrm{mM}$ TEA (for depolarizations up to $-25 \mathrm{mV}$ ) but a large outward current in the additional presence of $10 \mathrm{~mm} 4-\mathrm{AP}$. The current apparently induced by $4-\mathrm{AP}$ was first evident at voltages near $-60 \mathrm{mV}$ and increased up to voltages near $-30 \mathrm{mV}$. In 10 cells, the maximum outward current elicited (in the presence of $10 \mathrm{~mm}$ TEA) by a ramp at $20 \mathrm{mV} / \mathrm{s}$ from -98 to $-28 \mathrm{mV}$ was $1.6 \pm 0.8 \mathrm{pA}$; this increased to $83 \pm 33 \mathrm{pA}$ in the additional presence of $10 \mathrm{~mm}$ 4-AP. There was also a dramatic enhancement of the current evoked by ramps at speeds of $50 \mathrm{mV} / \mathrm{s}$, from $14 \pm 8 \mathrm{pA}$ in $10 \mathrm{~mm}$ TEA to $215 \pm 77 \mathrm{pA}$ in $10 \mathrm{~mm}$ TEA plus $10 \mathrm{~mm} 4$-AP $(n=10)$. With ramp speed of $50 \mathrm{mV} / \mathrm{s}$, the voltage at which maximal current was reached during the ramp from -98 to $-28 \mathrm{mV}$ also changed, from $-56 \pm 3 \mathrm{mV}$ in $10 \mathrm{~mm}$ TEA to $-28 \mathrm{mV}$ in $10 \mathrm{~mm}$ TEA plus $10 \mathrm{~mm} 4-\mathrm{AP}(n=10)$. With a ramp speed of $100 \mathrm{mV} / \mathrm{s}$, at which there was a larger current in the presence of $10 \mathrm{~mm}$ TEA alone, the effects of $10 \mathrm{~mm} 4$-AP were more complex. Here, there was an inhibition of current in the voltage range from -70 to about $-50 \mathrm{mV}$, followed by an enhancement of current positive to $-50 \mathrm{mV}$. In 10 cells studied with ramp speed of $100 \mathrm{mV} / \mathrm{s}$, 

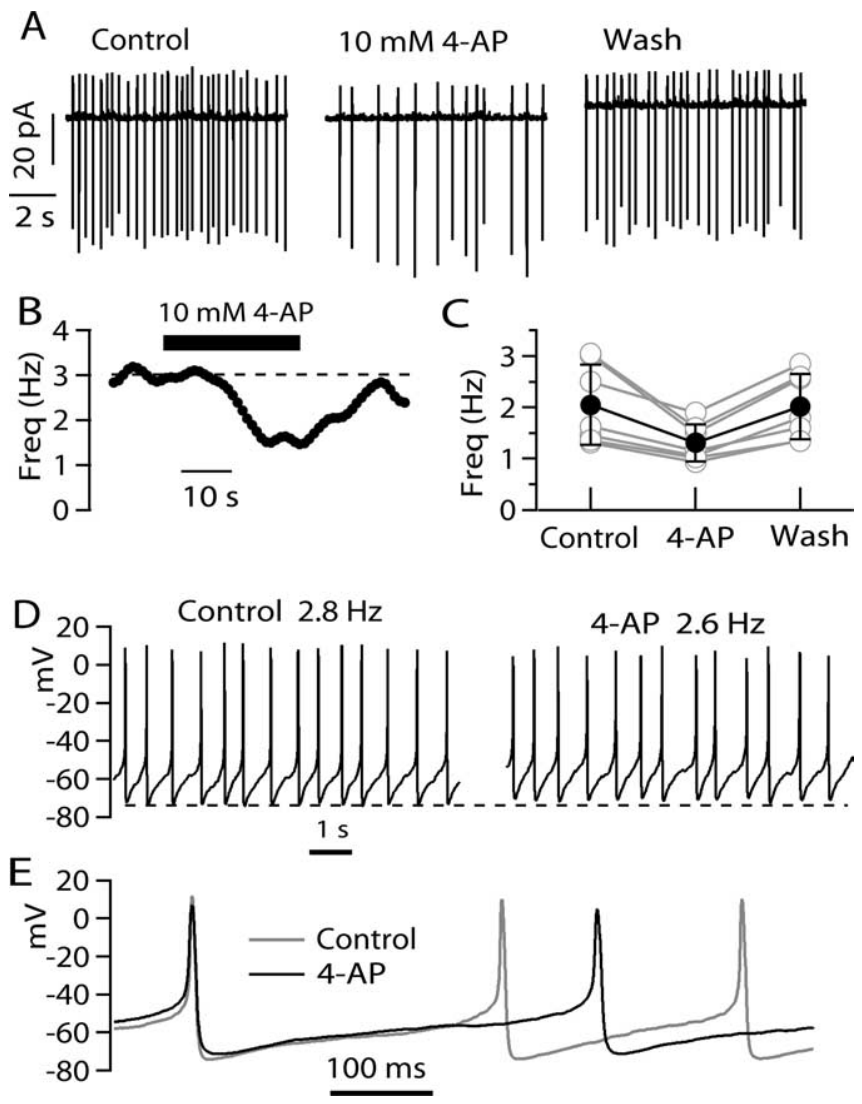

Figure 5. Effect of 4-AP on spontaneous firing of TMN neurons. A, Effect of $10 \mathrm{~mm}$ 4-AP on spontaneous firing of a TMN neuron recorded in cell-attached mode. Pipette contained the same solution as the bath (Tyrode's solution). B, Time course of 4-AP effect on firing (same cell as $\boldsymbol{A}$ ). The dashed line corresponds to average firing rate before application of 4-AP. C, Collected data for effects of $10 \mathrm{~mm} 4-\mathrm{AP}$ on spontaneous firing recorded in cell-attached mode. The solid line shows mean $\pm S D$. $\boldsymbol{D}$, Effect of $10 \mathrm{~mm}$ 4-AP on spontaneous firing recorded in whole-cell mode. The dashed line shows most negative voltage reached during the firing cycle in the control. Note that this shifts in the depolarizing direction with 4-AP. E, Superimposed recordings in $\boldsymbol{D}$, with spikes aligned at their peaks.

there was an inhibition of current at $-58 \mathrm{mV}$ from $41 \pm 14 \mathrm{pA}$ in $10 \mathrm{~mm}$ TEA to $20 \pm 11 \mathrm{pA}$ in $10 \mathrm{~mm}$ TEA plus $10 \mathrm{~mm} 4-\mathrm{AP}$, and an enhancement of peak current during the entire ramp, from $64 \pm 28 \mathrm{pA}$ in $10 \mathrm{mM}$ TEA (peak reached at $-46 \pm 5 \mathrm{mV}$ ) to $324 \pm 115 \mathrm{pA}$ in $10 \mathrm{~mm}$ TEA plus $10 \mathrm{~mm} 4$-AP (peak reached at $-28 \mathrm{mV}$ in all cells).

\section{Slowing of firing by 4 -AP}

The simplest interpretation of these results is that, although 4-AP effectively inhibits peak $I_{\mathrm{A}}$ when elicited by step depolarizations, it has complex effects on $I_{\mathrm{A}}$ evoked by ramps, producing a net enhancing effect that is especially striking at slower ramp speeds, at which activation of $I_{\mathrm{A}}$ is negligible in the absence of 4-AP. During spontaneous firing of tuberomammillary neurons, the voltage trajectory between spikes resembles depolarizing ramps at speeds in the range of $25-100 \mathrm{mV} / \mathrm{s}$, for which 4 -AP produces enhancing effects on $I_{\mathrm{A}}$. If $I_{\mathrm{A}}$ flows between spikes during pacemaking of TMN neurons, application of 4-AP might have the counterintuitive effect of slowing rather than speeding firing when applied to spontaneously firing neurons. We tested this possibility by making recordings of spontaneously firing tuberomammillary neurons in cell-attached mode, in which there is no dialysis of the cells and physiological ionic conditions are optimally preserved. Figure $5 A$ shows the effect of 4 -AP on spon- taneous firing of a tuberomammillary neuron studied with cellattached patch recording. In control conditions, the cell fired rhythmically at a frequency of $3.0 \mathrm{~Hz}$. On exchanging external solution to one containing $10 \mathrm{~mm} 4-\mathrm{AP}$, firing slowed to $1.6 \mathrm{~Hz}$. With removal of 4-AP, the effect reversed nearly completely over $\sim 60 \mathrm{~s}$ (Fig. $5 B$ ). Slowing of firing was seen in each of six cells studied with this protocol (Fig. $5 C$ ), with an average reduction of firing rate by $33 \pm 11 \%(p<0.005$, paired $t$ test $)$.

Slowing of firing by 4 -AP was also seen in experiments in whole-cell current clamp, although with this recording configuration the effect was smaller and less consistent. An example is shown in Figure $5 D$, in which the frequency of firing changed from 2.8 to $2.6 \mathrm{~Hz}$ on application of 4-AP. In eight cells tested in the whole-cell mode, the rate of firing rate was reduced in five cells, remained the same in one cell, and was enhanced slightly in two of eight cells. In all cells, there was a small depolarization of the membrane potential. When measured as the average membrane potential with spikes removed, there was on average a $+3.3 \pm 1.7 \mathrm{mV}$ depolarization produced by 4 -AP. Consistent with net depolarization of the membrane potential, both spike peak and the maximum rate of rise of the action potentials decreased, as expected for increased steady-state inactivation of sodium channel. However, the biggest effect on spike shape was a widening of the action potential, from a width (at half-maximum spike height) of $6.7 \pm 1.2 \mathrm{~ms}$ in control to $9.5 \pm 1.4 \mathrm{~ms}$ in the presence of $10 \mathrm{~mm} 4$-AP ( $n=8$; $p<0.001$, paired $t$ test).

It is not obvious why the effect of 4 -AP in slowing firing is smaller and less reliable in whole-cell recording compared with cell-attached recordings. The difference may be related to the fact that the rate of firing tended to be faster in the whole-cell recordings than in cell-attached recordings. With faster firing, there would be a faster rate of depolarization during the interspike interval, and with faster ramps, there was both inhibition as well as augmentation of the apparent $I_{\mathrm{A}}$ flowing during the ramp (Fig. $4 B$ ). Thus, it is plausible that there might be a balance of both effects occurring in faster-firing cells, with less net augmentation. Also, the faster firing in whole-cell mode may reflect depolarization of average membrane potential relative to the undisturbed situation in cell-attached mode, perhaps resulting from leak around the seal between pipette and cell membrane or a consequence of cell dialysis. Even a small net depolarization could significantly inactivate $I_{\mathrm{A}}$ flowing in the interspike intervals because of the steep slope factor of steady-state inactivation (Fig. $1 \mathrm{~B})$. It is also possible that 4 -AP has effects on other channel types (e.g., sodium channels or calcium channels or background $\mathrm{K}$ channels) whose activity might be affected by dialysis of the cells during whole-cell recording. In cell-attached mode, 4-AP appeared to produce a net hyperpolarization, in contrast to the net depolarization seen in whole-cell mode, because the action currents corresponding to the rate of rise of spikes increased in magnitude with 4-AP in cell-attached mode (Fig. 5A). Whatever the reason for the difference in magnitude of 4-AP effects in cellattached and whole-cell modes, the effects on firing in the cellattached mode are likely to reflect the least-disturbed, most physiological situation.

\section{Prolongation by 4-AP of anode break latency}

A common feature in neurons with prominent $I_{\mathrm{A}}$ is a long latency to firing a spike on anode break (Llinás and Alonso, 1992; Nisenbaum et al., 1994; Schoppa and Westbrook, 1999; Molineux et al., 2005; Koyama and Appel, 2006). The hyperpolarization acts to remove resting inactivation of $I_{\mathrm{A}}$, which can then activate on termination of the hyperpolarization, delaying the approach to 
A
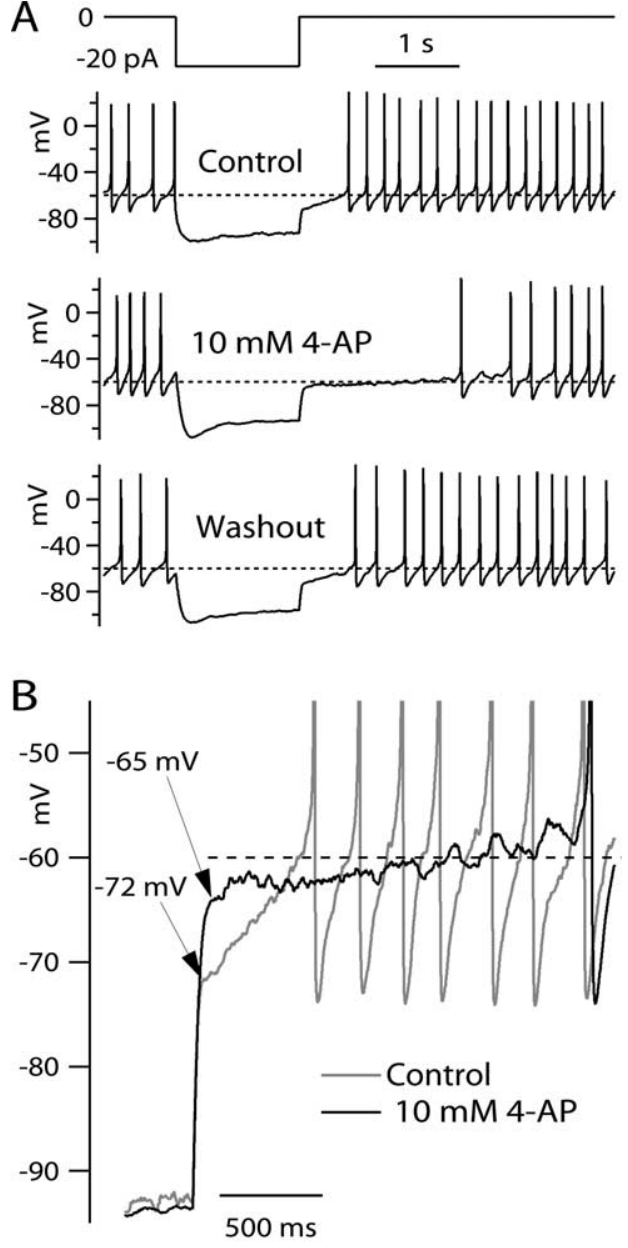

\section{C}
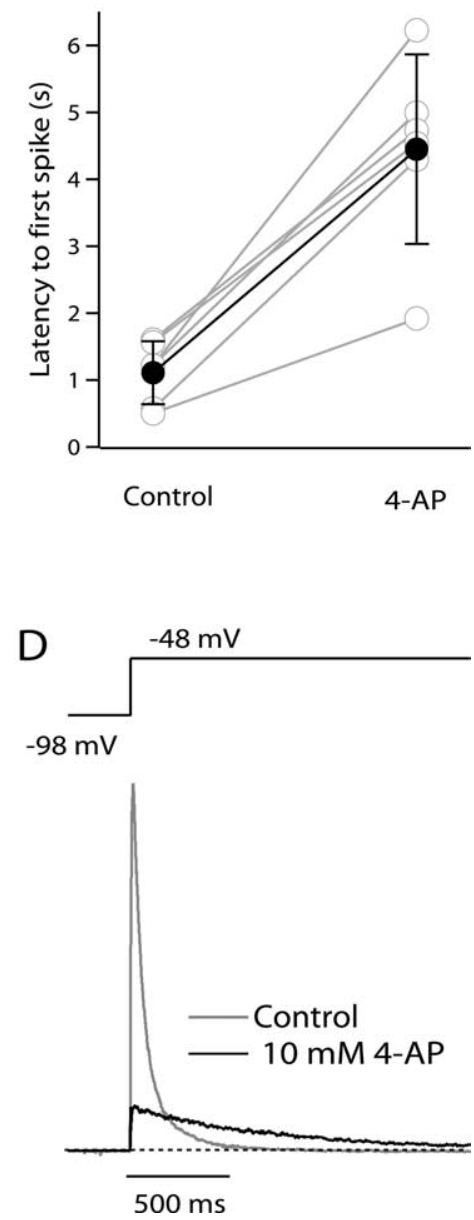

Figure 6. Effect of 4-AP on anode break latency. $A$, Effect of $10 \mathrm{~mm}$ 4-AP on response to a $20 \mathrm{pA}$ hyperpolarizing current pulse. In control (top), the hyperpolarization induces a delayed resumption of firing, with a delay of $\sim 600 \mathrm{~ms}$. In the presence of $10 \mathrm{~mm}$ 4-AP (middle), the latency to first peak was enhanced more than threefold, to $1970 \mathrm{~ms}$. The effect of 4-AP was completely reversible (bottom). The dashed lines are drawn at $-60 \mathrm{mV}$. $\boldsymbol{B}$, Higher-resolution display of voltage trajectories after termination of the hyperpolarizing current pulse. With 4-AP present, the initial depolarization on termination of the hyperpolarizing pulse was much faster than in control, and $50 \mathrm{~ms}$ after the termination, voltage in the presence of 4-AP reached $-65 \mathrm{mV}$ compared with $-72 \mathrm{mV}$ in control. However, after the first $200 \mathrm{~ms}$, the voltage in the presence of 4-AP moved in the hyperpolarizing direction, away from spike threshold, for $\sim 500$ ms before depolarization resumed. C, Collected results of the same experiment in six cells (gray symbols and lines), along with mean \pm SD (filled circles and error bars). $\boldsymbol{D}$, Currents elicited by a voltage-clamp protocol approximating the "off" of a hyperpolarization in current clamp, showing enhanced potassium current after $\sim 200$ ms that can account for the secondary hyperpolarization seen in the presence of 4-AP in the current-clamp experiments.

more than threefold, to $1970 \mathrm{~ms}$. On washout of the 4-AP, the latency returned to near the control value, at $683 \mathrm{~ms}$ (data not shown). The latency to first spike was similarly enhanced by 4-AP in six of six cells studied with this protocol, with the average increase in spike latency being a $4.4 \pm$ 1.7-fold enhancement (Fig. 6C). In collected results from six cells, the latency was $1.1 \pm 0.5 \mathrm{~s}$ in control and $4.5 \pm 1.4 \mathrm{~s}$ after application of $10 \mathrm{~mm} 4-\mathrm{AP}(p<0.001$, paired $t$ test). The most straightforward explanation of the effect of 4-AP in enhancing spike latency with this protocol is that 4-AP enhances $I_{\mathrm{A}}$ flowing as the cell depolarizes after the end of the hyperpolarizing pulse. This interpretation is supported by voltage-clamp mode experiments using a voltage command protocol that approximated the voltage trajectory during the anode break excitation in current clamp (Fig. 6D). From a steady holding voltage of $-48 \mathrm{mV}$, a 1.5-s-long pulse to $-98 \mathrm{mV}$ was delivered, followed by a return to $-48 \mathrm{mV}$. With this protocol, 4-AP strongly inhibited the peak current during the return to $-48 \mathrm{mV}$. However, after $\sim 250 \mathrm{~ms}$, the current in the presence of 4-AP was enhanced compared with control. This seems consistent with the current-clamp results, in which there appears to be delayed depolarization (or enhanced hyperpolarization) after 500-600 $\mathrm{ms}$ that accounts for the delay in firing seen in 4-AP. A notable feature of the effect of 4-AP in current clamp is that, immediately after the break of the hyperpolarizing pulse, the effect of 4-AP is to speed the return toward resting potential (Fig. $6 \mathrm{~A}$, arrows): the voltage in 4-AP is more depolarized for the first $500 \mathrm{~ms}$ and then more hyperpolarized after this. This fits well with the voltage-clamp results in which 4-AP strongly inhibits the peak current and enhances the current only later. spike threshold until $I_{\mathrm{A}}$ has partially inactivated. The latency to first spike is strongly influenced by the rate of inactivation of $I_{\mathrm{A}}$. If 4-AP simply blocked $I_{\mathrm{A}}$, one would expect it to reduce spike latency. However, the voltage trajectory after anode break has a waveform somewhere intermediate between a voltage step (approximated by the initial relaxation) and a ramp (the later, slower phase of depolarization reflecting inactivation of $I_{\mathrm{A}}$ ). Therefore, based on the voltage-clamp results, it is difficult to predict whether 4-AP would have a blocking effect (as during steps) or an enhancing effect (as during ramps) on $I_{\mathrm{A}}$ during anode break excitation. Figure 6 shows the effect of 4-AP on spike latency in anode break excitation. A $1.5 \mathrm{~s}, 20$ pA hyperpolarizing pulse was applied to a spontaneously firing TMN neuron. On release from the hyperpolarizing step, the latency to first peak, as measured by the time interval from the end of the hyperpolarizing step to the peak of the first action potential, was $\sim 600 \mathrm{~ms}$. With the application of $10 \mathrm{~mm} 4-\mathrm{AP}$, the latency to first peak was enhanced

\section{Kinetic model for 4-AP enhancement of $I_{\mathrm{A}}$}

We attempted to develop a model for 4-AP interaction with the potassium channels underlying $I_{\mathrm{A}}$ that could explain why rampevoked currents are enhanced by 4-AP, whereas step-evoked currents are inhibited. First, we constructed a kinetic model for the channels underlying $I_{\mathrm{A}}$ based on experimental records of potassium currents recorded in the presence of $10 \mathrm{mM}$ TEA to block the high-threshold component of potassium current in the cells. Currents recorded in the presence of $10 \mathrm{mM}$ TEA appeared to represent reasonably pure $I_{\mathrm{A}}$ (Fig. 7). A notable feature of inactivation of $I_{\mathrm{A}}$ in TMN neurons is that inactivation is fastest for steps to near $-50 \mathrm{mV}$ and is slower for greater depolarizations. The slower decay with increasing depolarization is opposite to what is seen for inactivation of sodium channels and most other voltagedependent channels. This behavior is evident for decay of the overall potassium currents in TMN neurons (Fig. 1), but the kinetics of overall currents are difficult to interpret, because for 
larger depolarizations, there are increasing amounts of non-inactivating components of current whose time course of activation might overlap with inactivation of the component from $I_{\mathrm{A}}$. When $I_{\mathrm{A}}$ is better isolated by application of $10 \mathrm{~mm}$ TEA (Fig. 7) to block overlapping non-inactivating currents, the slower time course of inactivation for larger depolarizations is even more evident (Fig. 7D). The experimental data of $I_{\mathrm{A}}$ recorded in the presence of 10 mM TEA to block other currents were used to develop a Markov state model for gating of $I_{\mathrm{A}}$ channels. The form of this model, shown in Figure 8, was based on previous models for gating of sodium channels (Kuo and Bean, 1994) and Kv4 channels (Bahring et al., 2001; Beck et al., 2002; Jerng et al., 2004a). In the model, activation of channels occurs along a pathway with strongly voltage-dependent rate constants; this pathway involves transitions between five closed states corresponding to sequential activation of four identical, independent voltage sensors, followed by an additional opening step. Inactivation can occur from any of the closed states. Individual rate constants for development and recovery from inactivation are not voltage dependent, but inactivation is allosterically coupled to the degree of activation, such that with progressive activation, the forward rate constant for inactivation is faster and recovery from inactivation is slower. The rate constants for the model were adjusted to approximately match predicted currents with experimental currents measured in $10 \mathrm{~mm}$ TEA, as in Figure 7. The ability of the model to match the voltage dependence and kinetics of these currents is consistent with their arising mainly from a homogeneous population of potassium channels. In the model, the slower decay of currents with increasing depolarization beyond $-50 \mathrm{mV}$ occurs because it is assumed that channels cannot inactivate from the open state. Thus, with increasing occupancy of the open state, macroscopic inactivation becomes slower. An interesting feature of the model is that, even at strongly negative voltages, channels are partly in the inactivated state (equal on and off rate constants for development of and recovery from inactivation between states $\mathrm{C} 1$ and I1). This appeared to be a necessary feature to account simultaneously for experimental voltage dependence of steady-state inactivation, voltage dependence of inactivation kinetics, relatively rapid kinetics of inactivation near $-50 \mathrm{mV}$ (time constant, 50-100 ms), and relatively slow recovery from inactivation (time constant, near $300 \mathrm{~ms}$ at $-100 \mathrm{mV}$ ). With the form of the model shown in Figure 8, it was possible to find rate constants that could provide a reasonable simulation of voltage dependence of activation, voltage dependence of steady-state inactivation, kinetics of activation, and kinetics of inactivation. With these rate constants, the model also provided a good simulation of the behavior of the current in response to ramp depolarizations at various speeds
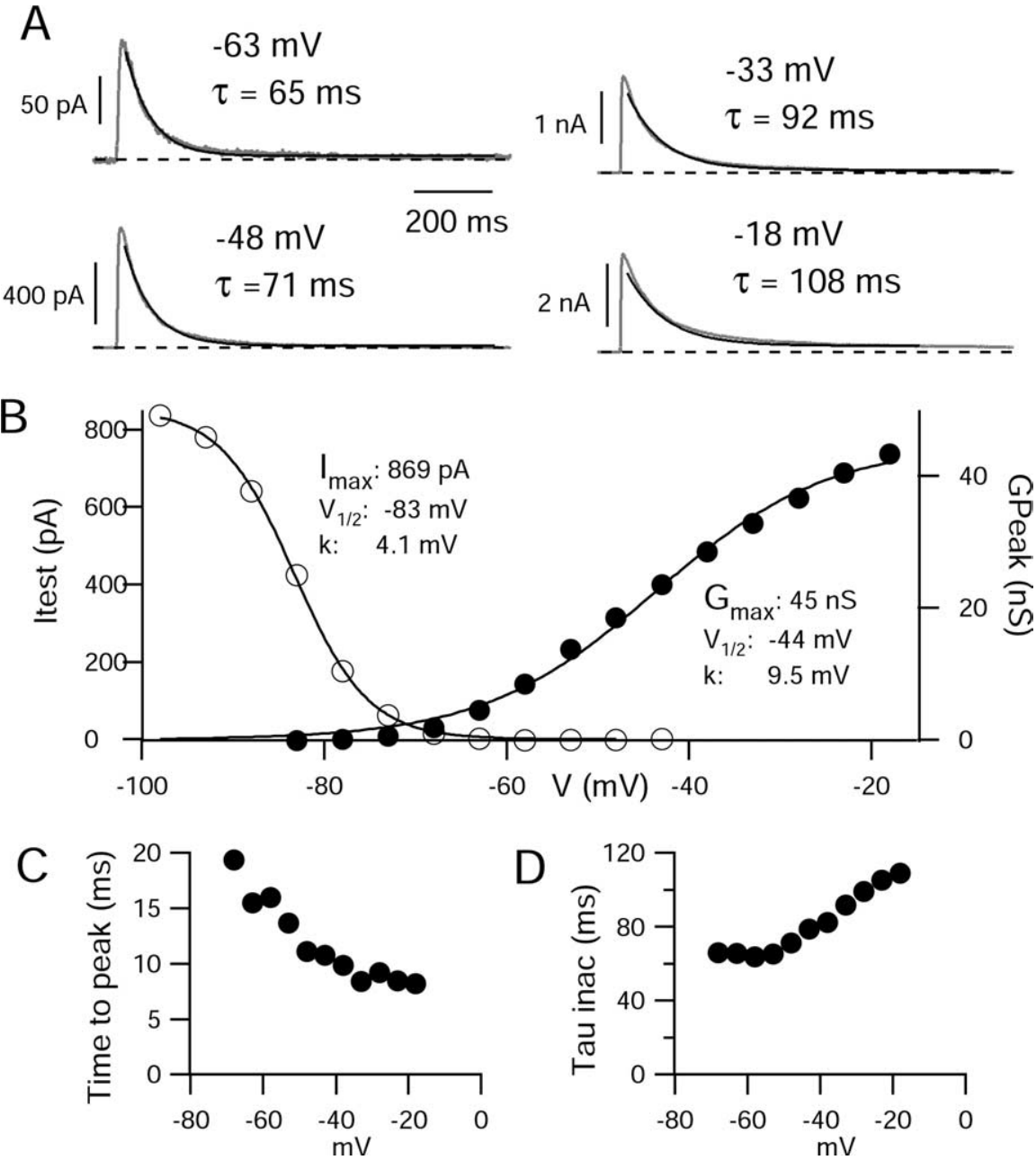

Figure 7. Isolation of $I_{A}$ for determination of kinetics and voltage dependence for modeling. Potassium currents recorded in the presence of $300 \mathrm{~nm}$ TTX and $10 \mathrm{~mm}$ TEA. $A$, Currents at four voltages with superimposed fits of a single exponential declining to zero, with the indicated time constants. $\boldsymbol{B}$, Voltage dependence of activation and inactivation. Voltage dependence of activation was potential, $E_{\mathrm{K}}$ (potassium equilibrium potential) $=-92 \mathrm{mV}, V_{\mathrm{h}}$ (midpoint) $=-44 \mathrm{mV}$, and $k$ (slope factor) $=9.5 \mathrm{mV}$. Voltage voltage. The solid curve through the open circles is drawn according to a Boltzmann curve describing inactivation, $I_{\max } /[1+$ $\left.\exp \left(\left(V-V_{\mathrm{h}}\right) / k\right)\right]$, with $I_{\max }=869 \mathrm{pA}, V_{\mathrm{h}}=-83 \mathrm{mV}$, and $k=4.1 \mathrm{mV}$. C, Time-to-peak of $I_{\mathrm{A}}$ as a function of voltage. D, Time constant of inactivation. Decay of current during a 2 s pulse was fit by a single exponential decay.

(Fig. 8, blue traces), with only very small currents evoked by slow ramps at $20 \mathrm{mV} / \mathrm{s}$ (because inactivation is nearly maximal before activation can occur) and increasingly large currents in response to ramps at 50 and $100 \mathrm{mV} / \mathrm{s}$.

To model the effects of 4-AP on ramps and steps, we found that the essential features could be predicted by making the basic assumption that 4-AP binds to closed and open states of the channel but not to inactivated states. This property of 4-AP binding to somatodendritic $I_{\mathrm{A}}$ channels is suggested by two features of 4-AP inhibition of $I_{\mathrm{A}}$ that have been previously observed in both neurons and cardiac muscle cells, as well as in our experiments: crossover of the decay phase of currents elicited in the presence of 4-AP with control currents, as in Figure 2 (Thompson, 1982; Kehl, 1990; Castle and Slawsky, 1992; Tseng et al., 1996), and "reverse use dependence," whereby 4-AP appears to unbind from channels with repeated depolarizations (Thompson, 1982; Tseng et al., 1996). In the model, 4-AP is assumed to bind to closed or open channels equally well, with a binding affinity corresponding 
A

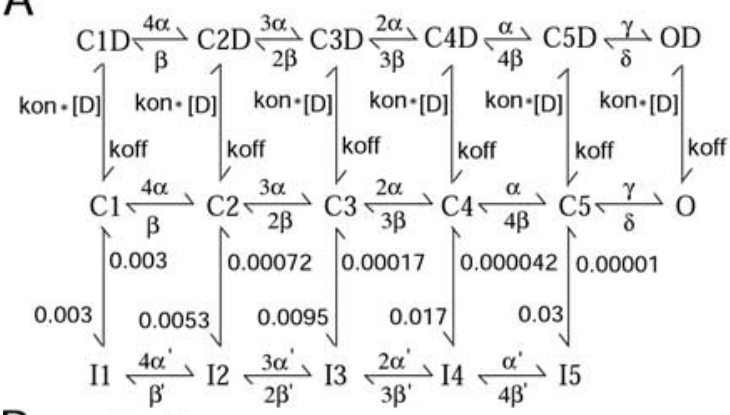

B

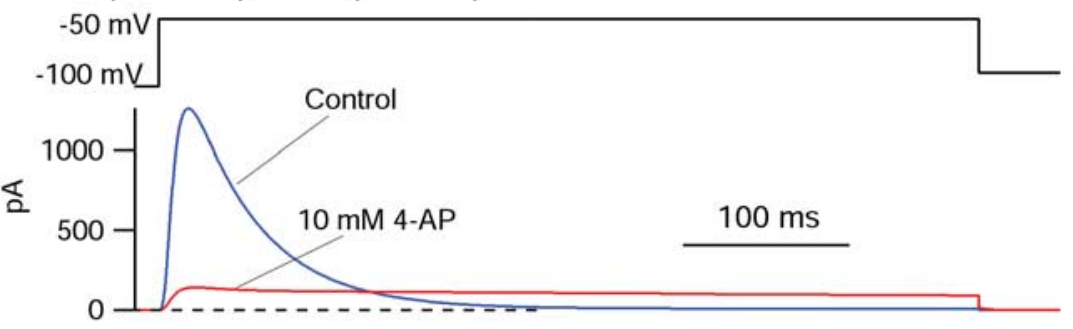

C

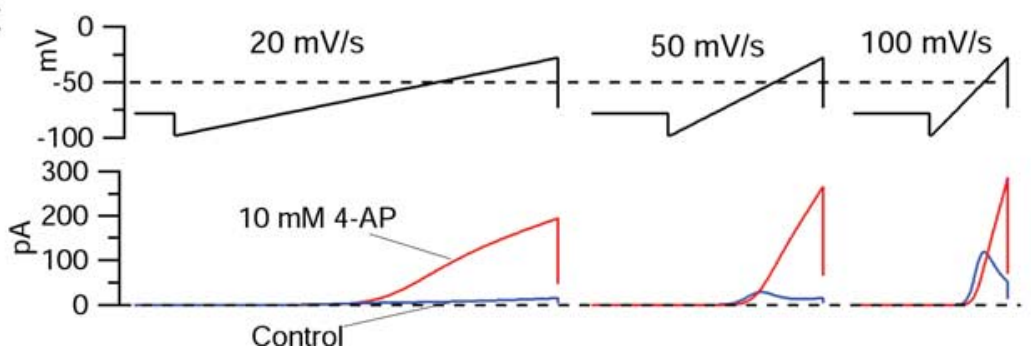

Figure 8. Kinetic model of $I_{A}$ and the effects of 4-AP on step-induced and ramp-induced currents. $A$, Activation occurs between closed states with voltage-dependent rate constants (middle row, ( states). The rate constants $\alpha$ and $\beta$ are strongly voltage dependent, as indicated. The rate constants $\gamma$ and $\delta$ govern a final opening step, which is weakly voltage dependent. Inactivation corresponds to movement from the middle row to the bottom row and occurs with rate constants that are not intrinsically voltage dependent, but whose values depend on the degree of activation. Binding of drug molecules $(D)$ is hypothesized to occur only to channels in the closed or open states, but not inactivated channels. Drug is hypothesized to bind with the same rate constants to all closed and open states. The binding and unbinding rate constants correspond to an $\mathrm{IC}_{50}$ of $1 \mathrm{~mm}$ (for inhibition of peak current elicited by step depolarizations from -100 to $-50 \mathrm{mV}$ ). B, Prediction of currents with and without $10 \mathrm{~mm}$ 4-AP elicited by a step from -100 to $-50 \mathrm{mV}$. Peak current is inhibited because of binding of drug to closed states. Channels cannot inactivate with drug bound. However, because the inactivated state is the favored state energetically at $-50 \mathrm{mV}$, channels move from the states in the top right to states in the bottom right, with a fraction of the channels passing through the open state as they move. This produces the prolonged current in the presence of drug that results in the crossover. C, Predictions of current with and without 10 $\mathrm{mm}$ 4-AP predicted by the model in response to ramps at 20,50 , and $100 \mathrm{mV} / \mathrm{s}$. The model captures the steep dependence of ramp-evoked currents on ramp speed under control conditions and also the dramatic enhancement of ramp current by 4-AP. The model was implemented in IGORPro, version 4.06, using fifth-order Runge-Kutta integration and a step size of $25 \mu$ s.

to a half-maximal effect of $1 \mathrm{~mm} 4$-AP when assayed by inhibition of peak $I_{\mathrm{A}}$ elicited from a negative holding potential (in which channels are in closed states).

The model is based on the idea that 4-AP molecules actually unbind from channels during long depolarizations that put most channels in inactivated states. If so, a prediction is that, after a long depolarization, a large fraction of channels will have no drug bound, and on repolarization, drug molecules will rebind as channels convert to closed states. Figure 9 shows an experiment designed to test this prediction. The cell was held steadily at -48 $\mathrm{mV}$, at which virtually all channels are inactivated. The cell was then hyperpolarized to $-98 \mathrm{mV}$ for various times to allow channels to progressively recover from inactivation back to closed, resting states. The extent of recovery was then assayed by $I_{\mathrm{A}}$ elicited by returning the voltage at $-48 \mathrm{mV}$. In control, channels recovered from inactivation exponentially, with a time constant of $\sim 300 \mathrm{~ms}$. In the presence of 4-AP, the behavior of currents after repolarization was more complex. Peak current followed a biphasic pattern, first increasing and then decreasing, reaching a maximum at $\sim 300 \mathrm{~ms}$ at $-98 \mathrm{mV}$. This is in accord with the model, which predicts that, in steady-state inactivation, drug molecules have unbound. As channels recover from inactivation and enter closed states, drug binds, producing the decline in peak test pulse current (Fig. 9E).

In the presence of 4-AP, the kinetics of the test current also changed as the repolarization increased (Fig. 9D). After short repolarizations, the test current was similar in kinetics to control current, decaying quickly. This is consistent with most channels being free of bound drug after the long period at $-48 \mathrm{mV}$, so that short periods of repolarization allow those channels to recover from inactivation before being bound by drug. However, after longer repolarizations, the decay of the test current was biphasic, with a rapid phase (which declined with longer repolarizations) and a slow phase (which increased with longer repolarizations). According to the model, the increasing fraction of the slow component reflects an increased fraction of channels being bound by drug as drug binding to closed states is enabled as channels move from inactivated states to closed states with increasing times at $-98 \mathrm{mV}$.

\section{Discussion \\ Properties of subthreshold $I_{\mathrm{A}}$}

In voltage-dependent sodium channels, inactivation is incomplete, so that there is a small (but physiologically significant) steady-state current in the subthreshold voltage range, sometimes evident as low as $-70 \mathrm{mV}$ and typically maximal near -40 $\mathrm{mV}$ (Crill, 1996; Taddese and Bean, 2002; Ptak et al., 2005). Similar steady-state currents have been reported for T-type calcium channels (Crunelli et al., 2005). However, our results suggest that $I_{\mathrm{A}}$ produces virtually no steady-state current of this type. For steps to voltages in the range from -70 to $-40 \mathrm{mV}$, decay of the current appeared to be complete within the resolution of the measurements. Consistent with this, although rampevoked current from $I_{\mathrm{A}}$ was measurable for ramps at speeds $>50$ $\mathrm{mV} / \mathrm{s}$, it was not evident for ramps slower than $20 \mathrm{mV} / \mathrm{s}$, suggesting that true steady-state current is negligible.

Although there appears to be no measurable $I_{\mathrm{A}}$ at subthreshold voltages at true steady state, there is substantial subthreshold $I_{\mathrm{A}}$ with moderately slow rates of depolarization $(50-100 \mathrm{mV} / \mathrm{s})$ like those seen during pacemaking. Thus, it is plausible that $I_{\mathrm{A}}$ might play a significant role in regulating pacemaking frequency in TMN neurons. However, the ramps were delivered from a steady holding voltage of $-98 \mathrm{mV}$, whereas during pacemaking in TMN neurons the most negative voltages reached are typically in the range from -80 to $-65 \mathrm{mV}$. Thus, a crucial issue for whether or not $I_{\mathrm{A}}$ actually does affect pacemaking is how com- 
plete steady-state inactivation of $I_{\mathrm{A}}$ is during the pacemaking cycle. We hoped to address this question by using 4-AP block to determine the magnitude of $I_{\mathrm{A}}$ flowing during the pacemaking cycle in cells firing at different rates, and to determine the effect of 4-AP on firing rate in currentclamp experiments. However, the enhancing effect of 4-AP for subthreshold currents obviously makes this impossible.

\section{Inhibition and enhancement of $I_{\mathrm{A}}$ by 4-AP}

We found that 4-AP has opposite effects on $I_{\mathrm{A}}$ depending on the time course of the depolarization used to activate $I_{\mathrm{A}}$, inhibiting peak $I_{\mathrm{A}}$ elicited by voltage steps but dramatically enhancing $I_{\mathrm{A}}$ elicited by slow depolarizing ramps. The enhancing effect was often $>10$-fold. The model suggests that the enhancement results from a statedependent interaction of 4-AP molecules with the potassium channels underlying $I_{\mathrm{A}}$ such that channels cannot inactivate with 4-AP bound (and conversely, that 4-AP cannot bind to inactivated channels). Thus, 4-AP binds to closed, resting channels and when bound blocks channel opening, thus inhibiting step-evoked current. But with slow ramps, where in the absence of drug channels become mostly inactivated, in the presence of drug channels fail to inactivate because of the initial presence of bound 4-AP, and current then flows as 4-AP unbinds from channels in the open state.

The enhancement of $I_{\mathrm{A}}$ by 4 -AP is also manifested in a less dramatic form as the crossover of step-evoked currents in the presence and absence of drug. According to the model shown in Figure 8, this phenomenon results from the same basic mechanism as the enhancement during ramps, namely the inability of 4-APbound channels to inactivate. This explanation for the crossover phenomenon was previously proposed for the effects of 4 -AP on $I_{\mathrm{A}}$ in molluscan neurons (Thompson, 1982) and cardiac muscle cells (Castle and Slawsky, 1992), and this proposal underlies the model in Figure 8. Although the dramatic enhancement of ramp-evoked currents by 4-AP has not been reported previously in other cell types, the crossover of step-evoked currents with and without 4-AP is evident in many previous records from diverse neuronal cell types (Thompson, 1982; Kehl, 1990; Castle and Slawsky, 1992; Tseng et al., 1996; Song et al., 1998; Hahn et al., 2003; Koyama and Appel, 2006). Thus, it seems likely that the phenomena we observed in tuberomammillary neurons are common to the many other neuronal types with 4-AP-sensitive $I_{\mathrm{A}}$ and that the enhancement of ramp-evoked currents would be seen in other cell types as well. The enhancement of ramp-evoked currents at subthreshold voltages is obviously highly relevant to physiological situations, because ramps of $20-100 \mathrm{mV} / \mathrm{s}$ approximate the voltage trajectory

E
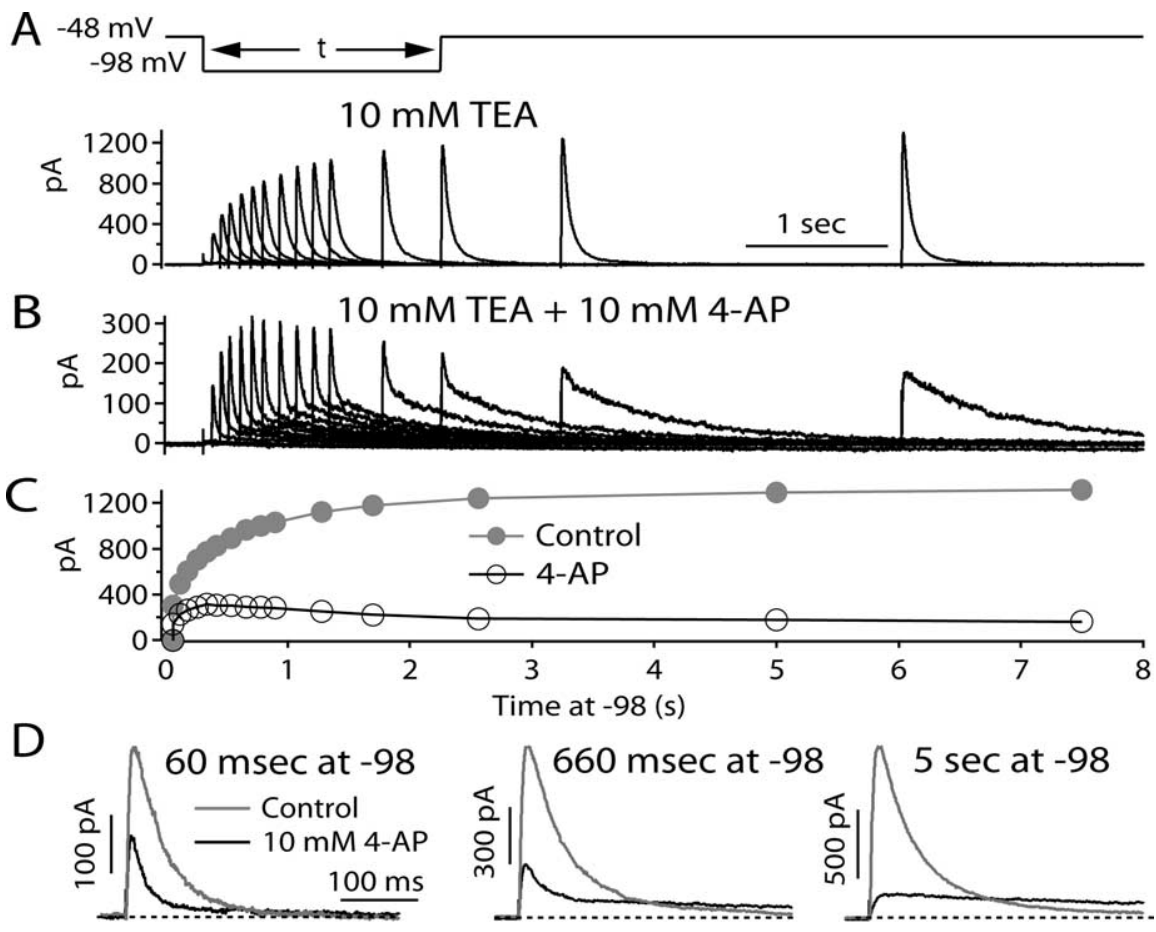

Figure 9. Evidence for unbinding and rebinding of 4-AP during long depolarizations and recovery. $\boldsymbol{A}$, Currents elicited under control conditions $\left(I_{A}\right.$ recorded in isolation in the presence of $300 \mathrm{~nm}$ TTX and $10 \mathrm{~mm}$ TEA) in response to a protocol in which pulse of varying duration to $-98 \mathrm{mV}$, after which the degree of recovery is assayed by a return to $-48 \mathrm{mV}$, eliciting $I_{\mathrm{A}}$ of as as size as the recovery period at $-98 \mathrm{mV}$ is prolonged. $\boldsymbol{B}$, Currents in response to the same protocol in the presence of 10 4-AP (open circles). D, Comparison of kinetics of test pulse currents with and without drug after recovery periods of $60 \mathrm{~ms}$ (1) Kinetics of control test pulse current do not depend on recovery time. With drug present, decay kinetics are similar to control after a short recovery, whereas after long recoveries, decay is very slow, as expected for a starting condition of drug bound channels. For intermediate times, test pulse current kinetics are biphasic, with one component similar to control and one moder the increasing fraction of the slow component represents drug binding as an increasing fraction of channels return from inactivated states to closed states with increasing times at $-98 \mathrm{mV}$. $\boldsymbol{E}$, Prediction of model in Figure 8 for the time course of availability [fractional occupancy of available states (i.e., non-inactivated states at $-48 \mathrm{mV}$, 4-AP unbinds nearly completely because channels are in inactivated states. On return to $-98 \mathrm{mV}$, initially channels recover from inactivation with a time course similar to control. As more channels recover into closed, resting states, these states bind 4-AP, resulting in a time-dependent decline in availability.

expected during the kind of slow repetitive firing regulated by $I_{\mathrm{A}}$ (whether spontaneous firing, as in TMN neurons, or elicited by steady current injection). The enhancement of subthreshold $I_{\mathrm{A}}$ can explain the seemingly paradoxical effect of 4-AP in slowing the spontaneous firing of TMN neurons.

\section{Effects on spike latency}

There are many cell types in which 4-AP produces a decrease in spike latency when rebound spikes follow hyperpolarization (Kanold and Manis, 1999; Burdakov et al., 2004; Molineux et al., 2005). Indeed, it is the effect of 4-AP in reducing this latency that is often taken as providing evidence that the latency is attributable to $I_{\mathrm{A}}$. The opposite effect of 4-AP to dramatically enhance spike latency in tuberomammillary neurons is therefore quite 
striking. However, the different effects of 4-AP on spike latencies among different cell types may not reflect any fundamental difference of 4-AP action on $I_{\mathrm{A}}$ but rather can be explained by differences in the duration of the latency under control conditions in the different cells. In TMN neurons, whether studied in brain slice (Llinás and Alonso, 1992) or after dissociation, as in our experiments, the latency to firing after hyperpolarizations (average of $\sim 1 s$ ) is longer than in most other cell types. The long latency is probably because $I_{\mathrm{A}}$ is by far the largest subthreshold current in TMN neurons, whereas T-type Ca current and $I_{\mathrm{h}}$, which produce earlier rebound firing, are comparatively small in TMN neurons. In cells with larger $I_{\mathrm{h}}$ and T-type Ca currents, the latency to rebound firing is expected to be a complicated function of the kinetics and magnitude of the inward currents from $I_{\mathrm{h}}$ and T-type Ca channels and the outward current from $I_{\mathrm{A}}$, all three of which are enhanced by longer and deeper hyperpolarizations but with different kinetics and voltage dependences (for detailed discussion, see Molineux et al., 2005). The effect of 4-AP on $I_{\mathrm{A}}$ elicited by voltage steps from -98 to $-48 \mathrm{mV}$ is to dramatically reduce the peak current but to enhance the current later in the pulse. Correspondingly, the effect on 4-AP on the voltage trajectory after a hyperpolarization in current clamp is to accelerate the initial return toward rest (for the first $500 \mathrm{~ms}$ ) and delay the later return (Fig. 6). So for cells in which the latency of rebound spike firing is less than $\sim 500 \mathrm{~ms}$, our results would predict that 4 -AP would speed the latency, whereas for cells in which the latency is $>500 \mathrm{~ms}$ (including TMN neurons), 4-AP is predicted to increase the latency. Consistent with this, cell types in which 4-AP has been reported to decrease the latency have all had control latencies < $500 \mathrm{~ms}$ (Kanold and Manis, 1999; Molineux et al., 2005). There are cell types in addition to TMN neurons with latencies $>500 \mathrm{~ms}$ (such as midbrain dopaminergic neurons, with latencies $\sim 800 \mathrm{~ms}$ ) (Koyama and Appel, 2006), but the effect of 4-AP on rebound latency has apparently not been reported for such cell types. It is also important to note that 4-AP has effects on potassium currents other than Kv4-mediated $I_{\mathrm{A}}$, including effects on Kv3-family channels (Rudy and McBain, 2001) and on the native subthreshold potassium current known as $I_{\mathrm{D}}$ (Storm, 1988; Nisenbaum et al., 1994; Locke and Nerbonne, 1997), with 10-fold lower half-blocking concentrations. It seems possible that the unexpected effects of 4-AP in slowing spontaneous firing and delaying latency of firing after a hyperpolarization are more obvious in TMN neurons because of the dominating role of $I_{\mathrm{A}}$ compared with other potassium currents.

\section{Molecular basis of $I_{\mathrm{A}}$ in TMN neurons}

In TMN neurons, the time constant for decay of $I_{\mathrm{A}}$ increases with depolarization, the opposite behavior to that most commonly seen for inactivation of voltage-activated channels. For cloned channels, this behavior has been described for Kv4.2 channels when coexpressed with accessory subunits likely present in native channels (Jerng et al., 2005), as well as for native currents in various types of neurons in which Kv4.2-containing channels likely predominate, including neostriatal cholinergic interneurons (Song et al., 1998; Tkatch et al., 2000) and hippocampal pyramidal neurons (Klee et al., 1995; Hoffman et al., 1997; Kim et al., 2005; Chen et al., 2006). We can speculate that the enhancing effect of 4-AP on subthreshold currents will also be present for channels made by Kv4.3 subunits, because the crossover of currents with and without 4-AP is also evident for $I_{\mathrm{A}}$ in midbrain dopaminergic neurons (Hahn et al., 2003) in which $I_{\mathrm{A}}$ is likely attributable primarily to Kv4.3 (Liss et al., 2001; Hahn et al., 2003). Thus the enhancing effect of 4-AP on Kv4-family- mediated somatodendritic $I_{\mathrm{A}}$ activated by slow, subthreshold depolarizations seems likely to be a widespread phenomenon.

\section{References}

Aghajanian GK (1985) Modulation of a transient outward current in serotonergic neurones by alpha 1-adrenoceptors. Nature 315:501-503.

Bahring R, Boland LM, Varghese A, Gebauer M, Pongs O (2001) Kinetic analysis of open- and closed-state inactivation transitions in human Kv4.2 A-type potassium channels. J Physiol (Lond) 535:65-81.

Beck EJ, Bowlby M, An WF, Rhodes KJ, Covarrubias M (2002) Remodelling inactivation gating of Kv4 channels by KChIP1, a small-molecular-weight calcium-binding protein. J Physiol (Lond) 538:691-706.

Bouskila Y, Dudek FE (1995) A rapidly activating type of outward rectifier $\mathrm{K}^{+}$current and A-current in rat suprachiasmatic nucleus neurones. J Physiol (Lond) 488:339-350.

Burdakov D, Alexopoulos H, Vincent A, Ashcroft FM (2004) Low-voltageactivated A-current controls the firing dynamics of mouse hypothalamic orexin neurons. Eur J Neurosci 20:3281-3285.

Castle NA, Slawsky MT (1992) Characterization of 4-aminopyridine block of the transient outward $\mathrm{K}^{+}$current in adult rat ventricular myocytes. J Pharm Exp Ther 264:1450-1459.

Chen X, Yuan LL, Zhao C, Birnbaum SG, Frick A, Jung WE, Schwarz TL, Sweatt JD, Johnston D (2006) Deletion of Kv4.2 gene eliminates dendritic A-type $\mathrm{K}^{+}$current and enhances induction of long-term potentiation in hippocampal CA1 pyramidal neurons. J Neurosci 26:12143-12151.

Connor JA, Stevens CF (1971a) Voltage clamp studies of a transient outward membrane current in gastropod neural somata. J Physiol (Lond) 213:21-30

Connor JA, Stevens CF (1971b) Prediction of repetitive firing behaviour from voltage clamp data on an isolated neurone soma. J Physiol (Lond) 213:31-53.

Cooper EC, Milroy A, Jan YN, Jan LY, Lowenstein DH (1998) Presynaptic cocalization of Kv1.4-containing A-type potassium channels near excitatory synapses in the hippocampus. J Neurosci 18:965-974.

Crill WE (1996) Persistent sodium current in mammalian central neurons. Annu Rev Physiol 58:349-362.

Crunelli V, Toth TI, Cope DW, Blethyn K, Hughes SW (2005) The "window" T-type calcium current in brain dynamics of different behavioural states. J Physiol (Lond) 562:121-129.

Furukawa K, Ishibashi H, Akaike N (1994) ATP-induced inward current in neurons freshly dissociated from the tuberomammillary nucleus. J Neurophysiol 71:868-873.

Greene RW, Haas HL, Reiner PB (1990) Two transient outward currents in histamine neurones of the rat hypothalamus in vitro. J Physiol (Lond) 420:149-163.

Haas HL, Reiner PB (1988) Membrane properties of histaminergic tuberomammillary neurons of the rat hypothalamus in vitro. J Physiol (Lond) 399:633-646.

Hahn J, Tse TE, Levitan ES (2003) Long-term $\mathrm{K}^{+}$channel-mediated dampening of dopamine neuron excitability by the antipsychotic drug haloperidol. J Neurosci 23:10859-10866.

Hahn J, Kullmann PH, Horn JP, Levitan ES (2006) $\mathrm{D}_{2}$ autoreceptors chronically enhance dopamine neuron pacemaker activity. J Neurosci 26:5240-5247.

Hoffman DA, Magee JC, Colbert CM, Johnston D (1997) $\mathrm{K}^{+}$channel regulation of signal propagation in dendrites of hippocampal pyramidal neurons. Nature 387:869-875.

Huguenard JR, Coulter DA, Prince DA (1991) A fast transient potassium current in thalamic relay neurons: kinetics of activation and inactivation. J Neurophysiol 66:1304-1315.

Jerng HH, Qian Y, Pfaffinger PJ (2004a) Modulation of Kv4.2 channel expression and gating by dipeptidyl peptidase 10 (DPP10). Biophys J $87: 2380-2396$

Jerng HH, Pfaffinger PJ, Covarrubias M (2004b) Molecular physiology and modulation of somatodendritic A-type potassium channels. Mol Cell Neurosci 27:343-369.

Jerng HH, Kunjilwar K, Pfaffinger PJ (2005) Multiprotein assembly of Kv4.2, KChIP3 and DPP10 produces ternary channel complexes with ISA-like properties. J Physiol (Lond) 568:767-788.

Kanold PO, Manis PB (1999) Transient potassium currents regulate the dis- 
charge patterns of dorsal cochlear nucleus pyramidal cells. J Neurosci 19:2195-2208.

Kehl SJ (1990) 4-Aminopyridine causes a voltage-dependent block of the transient outward $\mathrm{K}^{+}$current in rat melanotrophs. J Physiol (Lond) 431:515-528.

Kim J, Wei DS, Hoffman DA (2005) Kv4 potassium channel subunits control action potential repolarization and frequency-dependent broadening in rat hippocampal CA1 pyramidal neurones. J Physiol (Lond) 569:41-57.

Klee R, Ficker E, Heinemann U (1995) Comparison of voltage dependent potassium currents in rat pyramidal neurons acutely isolated from hippocampal regions CA1 and CA3. J Neurophysiol 74:1982-1995.

Koyama S, Appel S (2006) A-type $\mathrm{K}^{+}$current of dopamine and GABA neurons in the ventral tegmental area J Neurophysiol 96:544-554.

Kuo CC, Bean BP (1994) $\mathrm{Na}^{+}$channels must deactivate to recover from inactivation. Neuron 12:819-829.

Liss B, Franz O, Sewing S, Bruns R, Neuhoff H, Roeper J (2001) Tuning pacemaker frequency of individual dopaminergic neurons by $\mathrm{Kv} 4.3 \mathrm{~L}$ and KChip3.1 transcription. EMBO J 20:5715-5724.

Llinás RR, Alonso A (1992) Electrophysiology of the mammillary complex in vitro. I. Tuberomammillary and lateral mammillary neurons. J Neurophysiol 68:1307-1320.

Locke RE, Nerbonne JM (1997) Three kinetically distinct $\mathrm{Ca}^{2+}$ independent depolarization-activated $\mathrm{K}^{+}$currents in callosal-projecting rat visual cortical neurons. J Neurophysiol 78:2309-2320.

Malin SA, Nerbonne JM (2000) Elimination of the fast transient in superior cervical ganglion neurons with expression of KV4.2W362F: molecular dissection of $I_{\mathrm{A}}$. J Neurosci 20:5191-5199.

Mayer ML, Sugiyama K (1988) A modulatory action of divalent cations on transient outward current in cultured rat sensory neurones. J Physiol (Lond) 396:417-433.

Molineux ML, Fernandez FR, Mehaffey WH, Turner RW (2005) A-type and T-type currents interact to produce a novel spike latency-voltage relationship in cerebellar stellate cells. J Neurosci 25:10863-10873.

Neher E (1992) Correction for liquid junction potentials in patch clamp experiments. Methods Enzymol 207:123-131.

Nisenbaum ES, Xu ZC, Wilson CJ (1994) Contribution of a slowly inactivating potassium current to the transition to firing of neostriatal spiny projection neurons. J Neurophysiol 71:1174-1189.

Ptak K, Zummo GG, Alheid GF, Tkatch T, Surmeier DJ, McCrimmon DR (2005) Sodium currents in medullary neurons isolated from the preBotzinger complex region. J Neurosci 25:5159-5170.

Rudy B, McBain CJ (2001) Kv3 channels: voltage-gated $\mathrm{K}^{+}$channels designed for high-frequency repetitive firing. Trends Neurosci 24:517-526.

Rush ME, Rinzel J (1995) The potassium A-current, low firing rates and rebound excitation in Hodgkin-Huxley models. Bull Math Biol 57:899-929.

Schoppa NE, Westbrook GL (1999) Regulation of synaptic timing in the olfactory bulb by an A-type potassium current. Nat Neurosci 2:1106-1113.
Segal M, Rogawski MA, Barker JL (1984) A transient potassium conductance regulates the excitability of cultured hippocampal and spinal neurons. J Neurosci 4:604-609.

Serodio P, Rudy B (1998) Differential expression of Kv4 $\mathrm{K}^{+}$channel subunits mediating subthreshold transient $\mathrm{K}^{+}$(A-type) currents in rat brain. J Neurophysiol 79:1081-1091.

Sheng M, Tsaur ML, Jan YN, Jan LY (1992) Subcellular segregation of two A-type $\mathrm{K}^{+}$channel proteins in rat central neurons. Neuron 9:271-284.

Shibata R, Nakahira K, Shibasaki K, Wakazono Y, Imoto K, Ikenaka K (2000) A-type $\mathrm{K}^{+}$current mediated by the $\mathrm{Kv} 4$ channel regulates the generation of action potential in developing cerebellar granule cells. J Neurosci 20:4145-4155.

Song WJ (2002) Genes responsible for native depolarization-activated $\mathrm{K}^{+}$ currents in neurons. Neurosci Res 42:7-14.

Song WJ, Tkatch T, Baranauskas G, Ichinohe N, Kitai ST, Surmeier DJ (1998) Somatodendritic depolarization-activated potassium currents in rat neostriatal cholinergic interneurons are predominantly of the A type and attributable to coexpression of Kv4.2 and Kv4.1 subunits. J Neurosci 18:3124-3137.

Stevens DR, Haas HL (1996) Calcium-dependent prepotentials contribute to spontaneous activity in rat tuberomammillary neurons. J Physiol (Lond) 493:747-754.

Storm JF (1988) Temporal integration by a slowly inactivating $\mathrm{K}^{+}$current in hippocampal neurons. J Physiol (Lond) 336:379-381.

Strassle BW, Menegola M, Rhodes KJ, Trimmer JS (2005) Light and electron microscopic analysis of KChIP and Kv4 localization in rat cerebellar granule cells. J Comp Neurol 484:144-155.

Taddese A, Bean BP (2002) Subthreshold sodium current from rapidly inactivating sodium channels drives spontaneous firing of tuberomammillary neurons. Neuron 33:587-600.

Thompson S (1982) Aminopyridine block of transient potassium current. J Gen Physiol 80:1-18.

Tkatch T, Baranauskas G, Surmeier DJ (2000) Kv4.2 mRNA abundance and A-type $\mathrm{K}^{+}$current amplitude are linearly related and A-type $\mathrm{K}^{+}$current amplitude are linearly related in basal ganglia and basal forebrain neurons. J Neurosci 20:579-588.

Tseng GN, Jiang M, Yao JA (1996) Reverse use dependence of Kv4.2 blockade by 4-aminopyridine. J Pharmacol Exp Ther 279:865-876.

Uteshev V, Stevens DR, Haas HL (1995) A persistent sodium current in acutely isolated histaminergic neurons from rat hypothalamus. Neuroscience 66:143-149.

Yuan W, Burkhalter A, Nerbonne JM (2005) Functional role of the fast transient outward $\mathrm{K}^{+}$current $I_{\mathrm{A}}$ in pyramidal neurons in (rat) primary visual cortex. J Neurosci 25:9185-9194.

Zbicz KL, Weight FF (1985) Transient voltage and calcium-dependent outward currents in hippocampal CA3 pyramidal neurons. J Neurophysiol 53:1038-1058 